\title{
Prediction of immunoglobulin G content in bovine colostrum by near-infrared spectroscopy
}

\author{
M. J. Rivero, ${ }^{\star} \dagger$ X. Valderrama, ${ }^{\star}$ D. Haines, $\neq$ and D. Alomar ${ }^{* 1}$ \\ *Instituto Producción Animal, and \\ †Escuela de Graduados, Facultad de Ciencias Agrarias, Universidad Austral de Chile, Valdivia, Chile 5090000 \\ ‡Department of Veterinary Microbiology, Western College of Veterinary Medicine, University of Saskatchewan, Saskatoon S7N 0M3, Canada
}

\begin{abstract}
The objective of this work was to assess the potential of near infrared spectroscopy to predict the immunoglobulin $\mathrm{G}$ ( $\operatorname{IgG}$ ) content in bovine colostrum. Liquid colostrum samples $(\mathrm{n}=157)$ were collected from Holstein cows from 2 dairy farms in southern Chile. Samples were obtained within $1 \mathrm{~h}$ of parturition and scanned in folded transmission (transflectance) in the visible-near infrared range. Multivariate regression models (modified partial least squares) were developed with spectral data against IgG content measured by radial immunodiffusion. The best calibration included a mathematical treatment of the spectra by a second derivative plus standard normal variate and detrending. The best equation explained a high proportion of the variation in $\operatorname{IgG}$ content $\left(\mathrm{R}^{2}\right.$ of 0.95 in calibration and 0.94 in cross-validation). Average $(91.5 \mathrm{~g} / \mathrm{L})$, standard deviation $(37.6 \mathrm{~g} / \mathrm{L})$, and range, as highest minus lowest values $(171.9 \mathrm{~g} / \mathrm{L})$ of reference values were 10.1, 4.2 , and 19 times the value of the root mean square error of cross-validation $(9.03 \mathrm{~g} / \mathrm{L})$ respectively. Nearinfrared spectroscopy, scanned in folded transmission, is an effective tool to predict the IgG content in liquid colostrum.
\end{abstract}

Key words: colostrum quality, immunoglobulin G, near-infrared spectroscopy, transflectance

\section{INTRODUCTION}

Adequate passive transfer of immunoglobulins is critical to the survival and health of young mammal (Chigerwe et al., 2008) either via the placenta, in those species where placental transfer is effective, or postnatally via colostrum in those where it is not, such as in ruminants (Stelwagen et al., 2009). Colostrum contains a high concentration of immunoglobulins that provide protection against microbial infection (Wheeler et al., 2007). Although bovine colostrum contains 3 major

Received May 13, 2011.

Accepted November 3, 2011.

${ }^{1}$ Corresponding author: dalomar@uach.cl classes of immunoglobulin: IgG, IgM, and IgA (Korhonen et al., 2000), IgG (particularly $\operatorname{IgG}_{1}$ ) is the most abundant in bovine colostrum (Stelwagen et al., 2009), comprising around 80 to $90 \%$ of the immunoglobulins in bovine colostral whey (Korhonen et al., 2000; ElLoly, 2007).

Factors associated with successful immunity transfer in the newborn calf are related to colostrum management, including concentration and volume of colostrum fed, time of feeding after birth, and minimal bacterial contamination of colostrum (Beam et al., 2009). An accurate method to measure $\operatorname{IgG}$ content is essential to assess colostrum quality. Several techniques have been developed. Radial immunodiffusion (RID), developed by Mancini et al. (1965), is considered the gold standard (Tyler et al., 1999; Bielmann et al., 2010). In RID, samples containing IgG are applied to small circular wells cut in an agarose gel that contains an antiserum to the immunoglobulin being evaluated. Measurement is based on the formation of a visible ring of antigen-antibody precipitin (Gapper et al., 2007). Other techniques to estimate colostral IgG are the use of hydrometer (Chigerwe et al., 2008; Rudovsky et al., 2008), weight of the first milking (Chigerwe et al., 2008), colostrum color (Argüello et al., 2005), refractometry (Chavatte et al., 1999; Bielmann et al., 2010), size-exclusion HPLC (Dolman and Thorpe, 2002), electrophoresis (Page and Thorpe, 2002), and protein affinity liquid chromatography (Abernethy and Otter, 2010). For an extensive review of the topic, the reader is referred to Gapper et al. (2007). However, like RID, most of these methods are impractical for field situations, because time to results can exceed $24 \mathrm{~h}$. Digital and optical refractometers have been tested as practical management tools and found capable of differentiating between good and poor quality colostrum, but variations in total solids, casein micelles, and fat globules can affect accuracy of the readings (Bielmann et al., 2010).

Near-infrared spectroscopy (NIRS) is a widely used method for evaluating food and feedstuffs. It has many advantages over other techniques: it is fast, accurate, 
and easily performed, and it provides objective data (Givens et al., 1997; Dračková et al., 2008). The nearinfrared (NIR) spectrum originates from overtones and combinations (weaker signals) from the fundamental vibrations that occur in the infrared region, to the $\mathrm{H}-$ containing groups in biological macromolecules, with overlapping absorption bands. The method requires appropriate calibrations to extract relevant information to develop a useful model to predict the analyte of interest or a particular quality of the samples (Osborne et al., 1993; Miller, 2001; Bosco, 2010). A critical aspect to consider is that prediction errors can stem from several factors associated with the samples, the instrument, the operators, and the reference techniques, as NIRS is a secondary technique, relying on the model developed from the spectral data and reference values (Williams and Norris, 2001). This method has been used extensively to evaluate food quality in general (Cen and He, 2007), including milk composition (Laporte and Paquin, 1999; Kawamura et al., 2007; Wu et al., 2008) and SCC (Tsenkova et al., 2001). However, despite the ample body of literature on NIRS applications to predict composition and quality traits of different foods and agricultural products, including prediction of main components of bovine colostrum (Navrátilová et al., 2006), no studies have reported the analysis of IgG content in colostrum by this technique. Therefore, the objective of this work was to evaluate the potential of NIRS technology to predict the IgG content in liquid colostrum from dairy cows.

\section{MATERIALS AND METHODS}

\section{Colostrum Samples}

The study was performed using 157 samples of colostrum collected from Holstein-Friesian cows of different parities, with average production of $7,000 \mathrm{~L}$, from 2 commercial dairy farms with spring and autumn calving, respectively, located in the province of Valdivia, Región de Los Ríos, southern Chile. Cows were fed on permanent pastures and supplemented with concentrate. Samples were collected from the colostrum obtained from the 4 quarters of the udders in the first hour after calving, thoroughly mixed, and divided into 2 subsamples, one for spectra collection and the other for reference analysis. All subsamples were stored at $-20^{\circ} \mathrm{C}$ until spectra collection and reference analysis were performed.

\section{Spectra Collection}

Prior to NIRS analysis, samples were thawed at 2 to $5^{\circ} \mathrm{C}$ for $24 \mathrm{~h}$, left for $10 \mathrm{~min}$ at room temperature $\left(18-20^{\circ} \mathrm{C}\right)$, and then agitated for 1 min with a vortex mixer at maximum speed to ensure a uniform dispersion of colostral components. Samples were scanned in the visible and near infrared (VIS-NIR) region (400-2,500 $\mathrm{nm}$, at 2-nm intervals) in a NIRSystems 6500 monochromator (Silver Springs, MD). The software WINISI II (Infrasoft International, Port Matilda, PA) was used for scanning and calibration. All samples were scanned in duplicate by transflectance (folded transmission). Each duplicate $(500 \mathrm{mg})$ was placed immediately after agitation in a cam-lock cell for liquid products with an aluminum reflector and 0.1-mm pathlength (part number IH-0345-1; NIRSystems). The transflectance cell was inserted in a spinning module (part number NR-6506; NIRSystems) for the readings. Each scan was composed of 32 readings of the sample plus 32 of a white ceramic tile provided in the instrument as a reference. The resulting spectra were recorded and stored in suitable files as $\log (1 / \mathrm{R})$, where $\mathrm{R}$ is the reflectance (in this case, transflectance) energy recovered by detectors in the VIS (silicon detectors) and NIR (lead sulfide detectors) range, positioned at $45^{\circ}$ of the sample.

\section{RID Assay}

Aliquots of colostrum samples reserved for reference analysis were thawed at 2 to $5^{\circ} \mathrm{C}$ for $24 \mathrm{~h}$ and then analyzed by RID at the Department of Veterinary Microbiology, Western College of Veterinary Medicine, University of Saskatchewan (Canada). The RID assay was performed using 1.0\% agar gel containing 2.5\% rabbit anti-bovine IgG (Jackson Laboratories Inc., West Grove, PA). Dilution series of test colostrum and reference colostrum were dispensed (5 replicates of 4 $\mu \mathrm{L}$ ) in wells ( $2 \mathrm{~mm}$ diameter) cut into the agar on the plate. Plates were incubated at 20 to $25^{\circ} \mathrm{C}$ for 18 to 24 $\mathrm{h}$ in a humid chamber, and ring diameters of precipitin surrounding the wells were measured using a RID plate reader (The Binding Site, Birmingham, UK). The content of $\operatorname{IgG}$ was determined using a regression line generated with 2 replicates of known standards (Bovine IgG Serum Calibrator, Midlands BioProducts Corp., Boone, IA) diluted serially $1 / 4$ to $1 / 32$ and incubated on each plate.

\section{Spectra Analysis}

A principal component analysis (PCA) was applied to raw spectral data $[\log (1 / \mathrm{R})]$ to highlight relevant absorption patterns. This technique is widely used in NIRS analysis as it is able to transform all the absorbance data in a few "synthetic" variables - linear combinations of the original data-called principal components (PC), which are uncorrelated and preserve 
the main variation of the spectra (Robert et al., 1996). The first PC reveal the main information in the data, whereas the last ones contains mostly noise. In this way, patterns of variability ("loadings") can be related to relevant absorption bands.

\section{Calibrations}

Modified partial least squares (MPLS) regression was used to obtain prediction equations, testing different mathematical treatments of the spectral data. Treatments consisted of gap-segment derivative, also referred to as subtraction order, or Norris derivative (Hopkins, 2001). No derivate (raw spectra), first and second derivatives were tested. Derivatives were applied across different data point intervals (gap) and with different smoothing segments of the spectra to resolve overlapping peaks and remove linear baselines (Osborne et al., 1993; Hruschka, 2001). Standard normal variate $(\mathbf{S N V})$ and detrending (DT) treatment were applied for scatter correction (Barnes et al., 1989). The SNV was applied to scale each spectrum by its own standard deviation and correct shifts in the $\mathrm{y}$-axis, and DT removes baseline curvature caused by interactions of moisture and particular effects across the NIR spectral range (Barnes et al., 1993). The option of no scatter correction was also tested. Equations were evaluated by one-out full cross-validation. This technique separates the calibration set into groups, omitting one for prediction and calibrating with the remaining groups. Four, 5, or 6 cross-validation groups were tested. If 4 groups are used, the first group is created from samples in position 1, 5, 9, and so on, and the second group, with samples in position 2, 6, 10, and so on. Consecutively, all groups were predicted and an error term; that is, standard error of cross-validation (Shenk and Westerhaus, 1996), also referred to as root mean square error of cross-validation (RMSECV), was computed. A coefficient of determination of crossvalidation $\left(\mathbf{R}^{2} \mathbf{C V}\right)$ was also calculated. Two passes of elimination of outliers were applied to remove aberrant predictions ("T" outliers) or abnormal spectra ("H" outliers). A critical value of 2.5 was set for $\mathrm{T}$ outliers (residuals of predicted vs. reference values) and of 10 for $\mathrm{H}$ outliers (distance between each spectrum and average spectra). Best equations were those with a lowest RMSECV, which is considered a good estimator of prediction accuracy (Infrasoft International). As a complementary criteria to select the best equation, the residual predictive deviation (RPD); that is, the relation between standard deviation of RID measurements (reference data) and the RMSECV, and the range error ratio (RER); that is, the relation between the range of RID values and the RMSECV, were used (Williams and Sobering, 1996; Williams 2001).

\section{RESULTS}

\section{Spectra}

Raw $(\log 1 / R)$ transflectance spectra of all fresh colostrum samples are shown in Figure 1a. Low, combined bands are present in the VIS range, albeit with high variability. Strong absorption bands are shown at 1,440 to 1,460 and 1,932 to $1,960 \mathrm{~nm}$, due to the high water content of samples. Standard deviation of the spectra (Figure 1b) reveals a strong variability along the VIS and NIR range, with 3 double variation peaks around $1,700,1,900$, and $2,300 \mathrm{~nm}$, suggesting a combination of absorption bands in the average spectrum.

The PCA restructured the spectral data into 11 synthetic, uncorrelated variables (PC) that comprised $99.97 \%$ of total variation. The first $4 \mathrm{PC}$ explained $98.1 \%$ of total variability (PC1: $70.5 \%, \mathrm{PC} 2: 21.6 \%$, PC3: $4.4 \%$, and PC4: $1.6 \%$ ). The patterns of spectral variation, or loadings, explained by the first $4 \mathrm{PC}$ (Figure 2) show several absorption bands: $\mathrm{PC} 1$ presented a flat trend and a few negative bands in the VIS and NIR sectors, whereas PC2 showed a positive signal in the early VIS (416-464 nm), a couple of negative bands at around $1,450 \mathrm{~nm}$ and $1,950 \mathrm{~nm}$, a weak positive signal at 1,720, and mixed bands from around 2,180 to 2,350 $\mathrm{nm}$. The loading values for PC3 reveal highly negative bands from 400 to $500 \mathrm{~nm}$ (VIS) and at 1,940 nm (NIR). It also depicted a broad positive signal at around 1,450, a peak at 1,884 , and combined smaller bands thereafter $(2,010$ to $2,100 \mathrm{~nm})$. Principal component 4 presented a high peak at around 440 and around 500 and $600 \mathrm{~nm}$ (VIS range). In the NIR range, a broad signal is present from 1,380 to $1,500 \mathrm{~nm}$, a well-defined band at 1,892 $\mathrm{nm}$, another at 1,980, and a mixed absorption at 2,060 to $2,076 \mathrm{~nm}$.

\section{RID Assay}

The IgG content of colostrum samples obtained by RID ranged from 1.7 to $185.4 \mathrm{~g} / \mathrm{L}$, with an average of $93.3 \mathrm{~g} / \mathrm{L}$ and a standard deviation of $37.9 \mathrm{~g} / \mathrm{L}$.

\section{Calibration}

Calibration statistics for the best equation developed are presented in Table 1. This calibration was performed with the full VIS and NIR segments of the electromagnetic range considering absorption values recorded every 8 data points $(16 \mathrm{~nm})$, which resulted in 


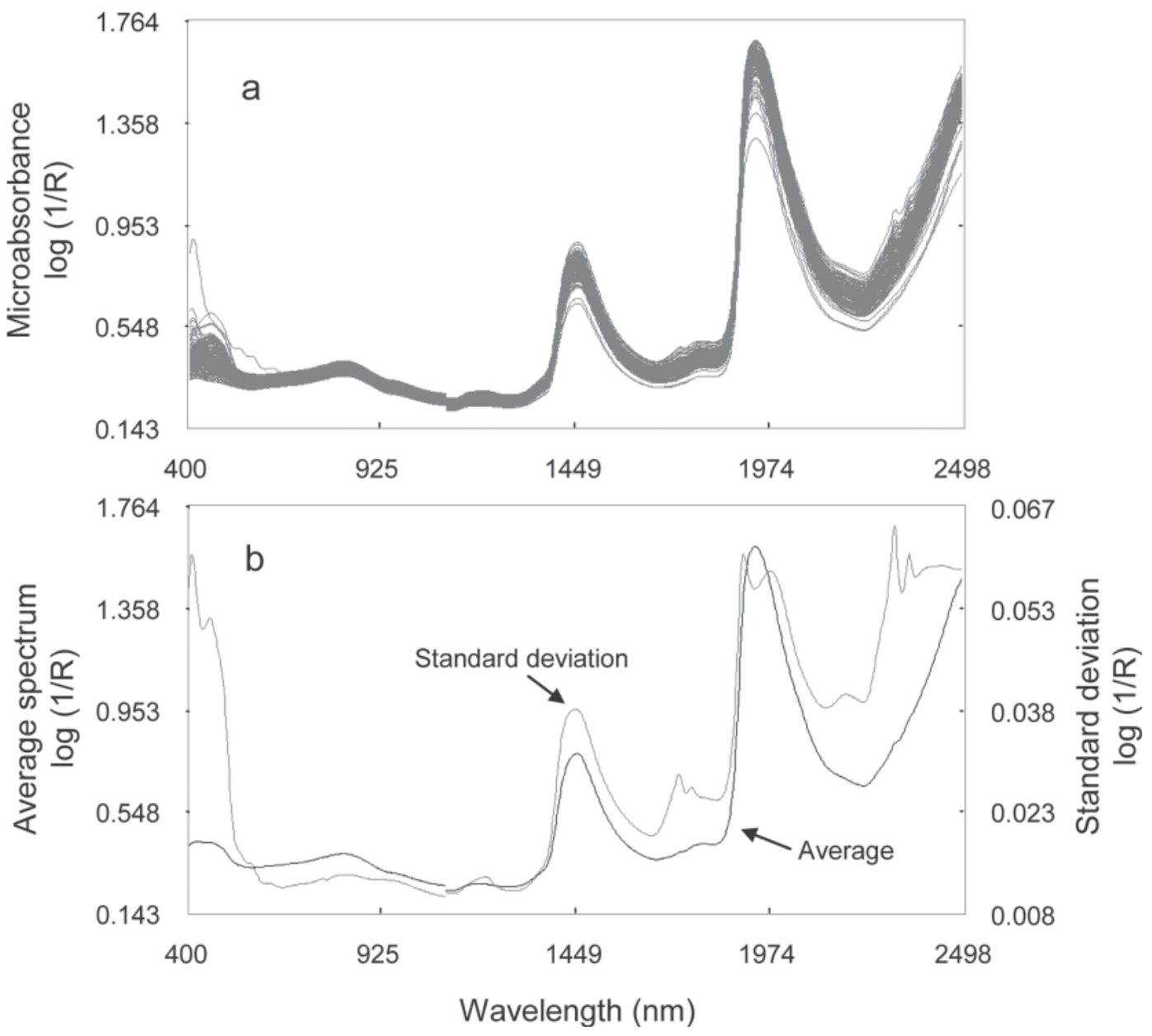

Figure 1. Visible and near infrared transflectance spectra of colostrum samples. (a) Complete calibration set; (b) average spectrum and standard deviation. $\mathrm{R}=$ reflectance.

computation of a total of 252 variables (wavelengths). A second derivative order was performed on the spectral values across a subtraction gap of $16 \mathrm{~nm}$ (8 data points) and a smoothing segment of $8 \mathrm{~nm}$ (4 data points). The SNV and DT algorithms were also applied. Eight samples with unusual prediction residuals and 1 with an abnormal spectrum were excluded from the calibration in 2 passes of elimination of outliers, resulting in a final inclusion of 148 samples. The prediction equation included 7 partial least squares terms. The selected equation performed slightly better than those obtained without derivatives or with a first derivative treatment.

\section{DISCUSSION}

This work evaluated the use of NIRS to assess colostrum quality of Holstein cows by the prediction of IgG content in liquid samples, by the use of folded transmission (transflectance).
The complex nature of the NIR spectra resulted from the multitude of overtone and combination bands produced by fundamental vibrations, in the mid infrared region, of several chemical groups, such as $\mathrm{OH}, \mathrm{CH}$, $\mathrm{NH}$, and $\mathrm{CO}$, which can present different configurations in a large group of molecules (Miller, 2001). The strong water absorptions observed at $980 \mathrm{~nm}$ and within the ranges of 1,440 to 1,460 and 1,932 to $1,960 \mathrm{~nm}$, were related to different order $\mathrm{OH}$ stretch overtones (Osborne et al., 1993; Miller, 2001). Wide variation can be observed in water absorption signals, which is probably due to different solid contents, among them lipids, which are known to cause important baseline shifts in the milk spectrum (Tsenkova et al., 2000) and, by extension, in colostrum. This is suggested in the present study by the standard deviation spectrum (Figure 1b), which shows a high diversity in other absorption bands that are concealed in the raw spectra by the water bands. That seems also to be the case in the range of 1,720 to $1,770 \mathrm{~nm}$ and at 2,308 $\mathrm{nm}$, where $\mathrm{CH}$ 
and the slight absorption signals involved were located in bands related to oil $(1,412 \mathrm{~nm})$, water $(1,420,1,940$ $\mathrm{nm})$, and protein $(1,924 \mathrm{~nm})$. This is coherent with the high light scattering in milk and colostrum explained by variations in water content, fat globules, and protein micelles (Šašic and Ozaki, 2001). The second PC loadings show clear bands associated negatively with $\mathrm{OH}$ in water $(1,420$ to $1,460 \mathrm{~nm}, 1,940 \mathrm{~nm})$ and positively with oil (1,725 nm and 2,300 to 2,340 nm). Loadings of PC3 indicated positive lipid $(1,412$ to 1,440$)$ and protein $(1,460 \mathrm{~nm})$ bands and a negative band for water $(1,940 \mathrm{~nm})$. A positive peak at $1,884 \mathrm{~nm}$ was also present, which could be attributed to a carboxyl group or to a disulfide bond (Miller, 2001). The same peak was present in the loadings of $\mathrm{PC} 4$, along with several other bands related to proteins. This finding is consistent with the fact that antibodies in general, and bovine IgG in particular, are made up of 4 protein chains (2 heavier and 2 lighter) hinged by disulfide bonds (Farrell et al., 2004).

With respect to the VIS range, positive and negative bands were present in loadings of the first $4 \mathrm{PC}$, and particularly in PC4. These were probably related to different types and content of carotenoids that influence the color of bovine colostrum (Calderón et al., 2007).

Mathematical treatments were applied to spectral data to decrease scatter, enhance bands, reduce bandshifts, and resolve mixed or overlapped absorptions. Figure 3 shows colostrum spectra after a second subtraction (derivative) order plus SNV and DT. Although higher variability can be seen in the VIS compared with the NIR segment, important information appeared in the latter region. As an example, in the encircled portion of Figure 3, a small segment was enhanced between 2,040 and 2,070 $\mathrm{nm}$, where combination bands of $\mathrm{N}-\mathrm{H}$ bonds associated with proteins are present. An important variation can be observed, representing different protein content in the samples. With a second derivative, absorption bands are shown as a minimum (negative values) at the peak value of the original spectrum (Hruschka, 2001). Therefore, samples with higher protein content should have higher magnitude negative peaks in this sector. Thus, these samples represent those with higher IgG concentrations, as globulins are the main protein fraction in colostrum. Plotting this spectral segment for the 5 samples with the highest and the 5 with the lowest IgG content (Figure 4) demonstrates the relevant differences in absorption; that is, immunoglobulin content.

The IgG content of the colostrum samples was highly variable and some samples had very low values. All samples were taken within $1 \mathrm{~h}$ after calving and before the newborn calf could nurse the dam. The very low IgG content of a few samples suggests that some cows may have experienced leaking of colostrum from the udder before calving. The variability in IgG content of the colostrum samples was desirable for this study, because a good calibration set should have a wide and evenly distributed composition (Murray, 1986).

The statistics of the selected equation showed a high coefficient of determination for the calibration $\left(\mathrm{R}^{2}\right)$ with a minor but expected reduction in $\mathrm{R}^{2} \mathrm{CV}$. A slight increase of error from calibration (standard error of calibration $=8.31 \mathrm{~g} / \mathrm{L}$ ) to cross validation (RMSECV $=9.03 \mathrm{~g} / \mathrm{L}$ ) was also expected and did not diminish the usefulness of the equation. Although RMSECV reached slightly more than 0.1 of the average $\mathrm{IgG}$ content of colostrum samples, the RPD and RER values allow routine operation of this equation with acceptable confidence. With a standard deviation equal to 4 times and a range of reference data almost 20 times the prediction error (Williams and Sobering, 1996; Williams, 2001), this equation could be used to predict IgG content of colostrum.

The encouraging results found in this study could be attributed in part to the ample variation of the reference data. However, the final equation was obtained without the inclusion of the sample with the highest IgG content $(185.4 \mathrm{~g} / \mathrm{L})$ because that sample was excluded as a $\mathrm{T}$ outlier in the calibration routine. The samples with abnormally low values (IgG content $<10$ $\mathrm{g} / \mathrm{kg}$ ) were not eliminated and several were well predicted. A new calibration was developed without these samples (data not shown) to explore how relevant these samples were for the quality of the equation obtained. The equation obtained presented RPD and RER values of 3.5 and 17.5, respectively, rendering it useful for prediction purposes. Either equation could be useful in programs to select animals as colostrum donors for pooling purposes or to obtain high quality colostrum.

Fourier-transform NIRS was successfully used by Navrátilová et al. (2006) to develop prediction models for the main components of bovine colostrum, including total solids, fat, and protein contents. They also used transflectance, which is a fast and easy method to obtain the readings in liquid samples or slurries. The use of a spinning module in a vertical plane for the cells, such as in the present work, is advantageous because rotation prevents fat globules from accumulating in the upper level of the cell. In fixed systems with transmittance or transflectance analysis of milk, movement of fat globules may cause a significant particle size effect that can affect the readings (Williams, 2001).

If reference values are plotted against NIRS predictions of $\operatorname{IgG}$ content obtained with the selected equation (Figure 5), a positive and close relationship can be observed, as values are distributed along and near the equal response $(\mathrm{y}=\mathrm{x})$ line. This was to be expected, 


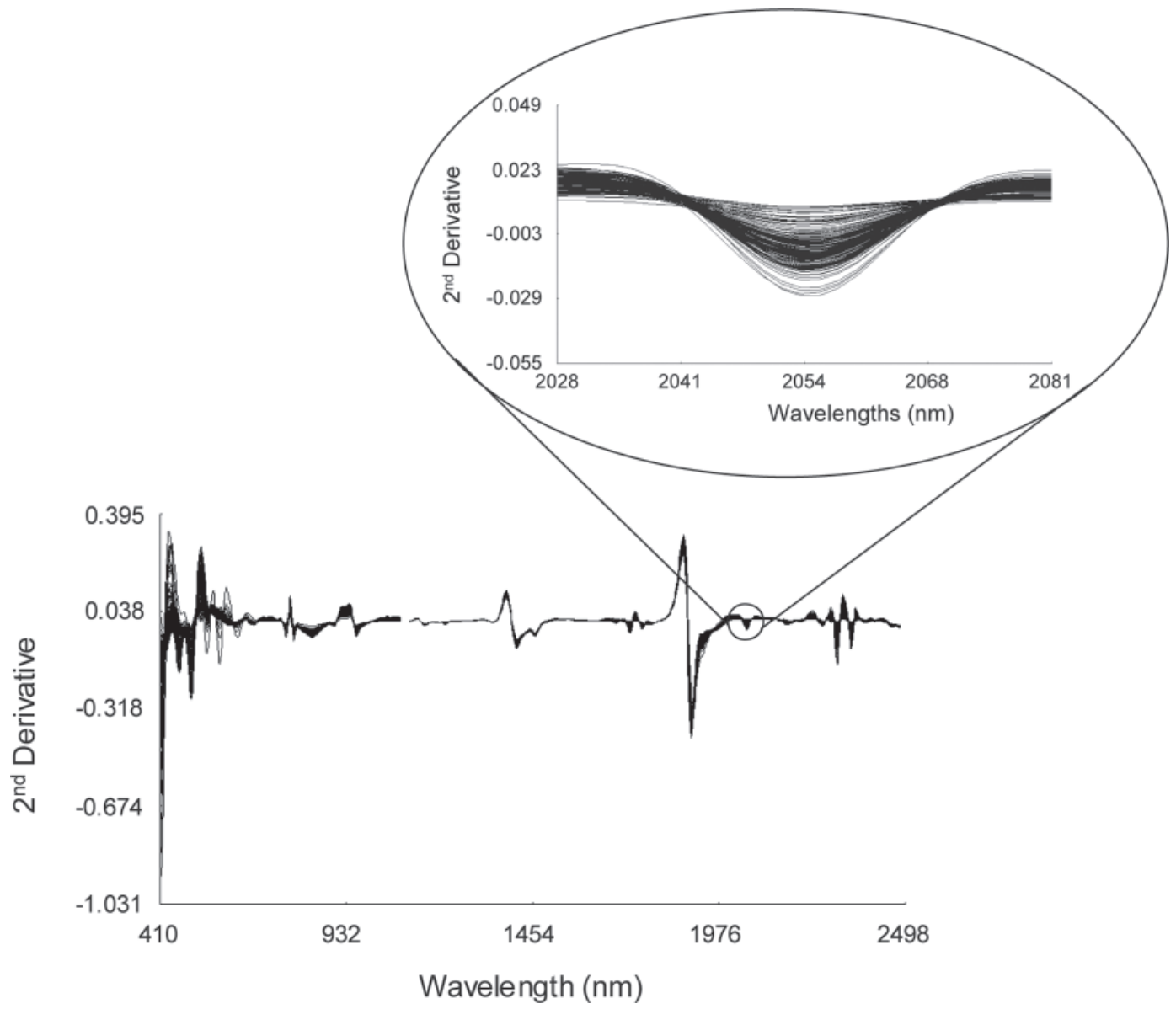

Figure 3. Second derivative of visible-near infrared reflectance spectra; the segment from 2,028 to $2,081 \mathrm{~nm}$ is enhanced.

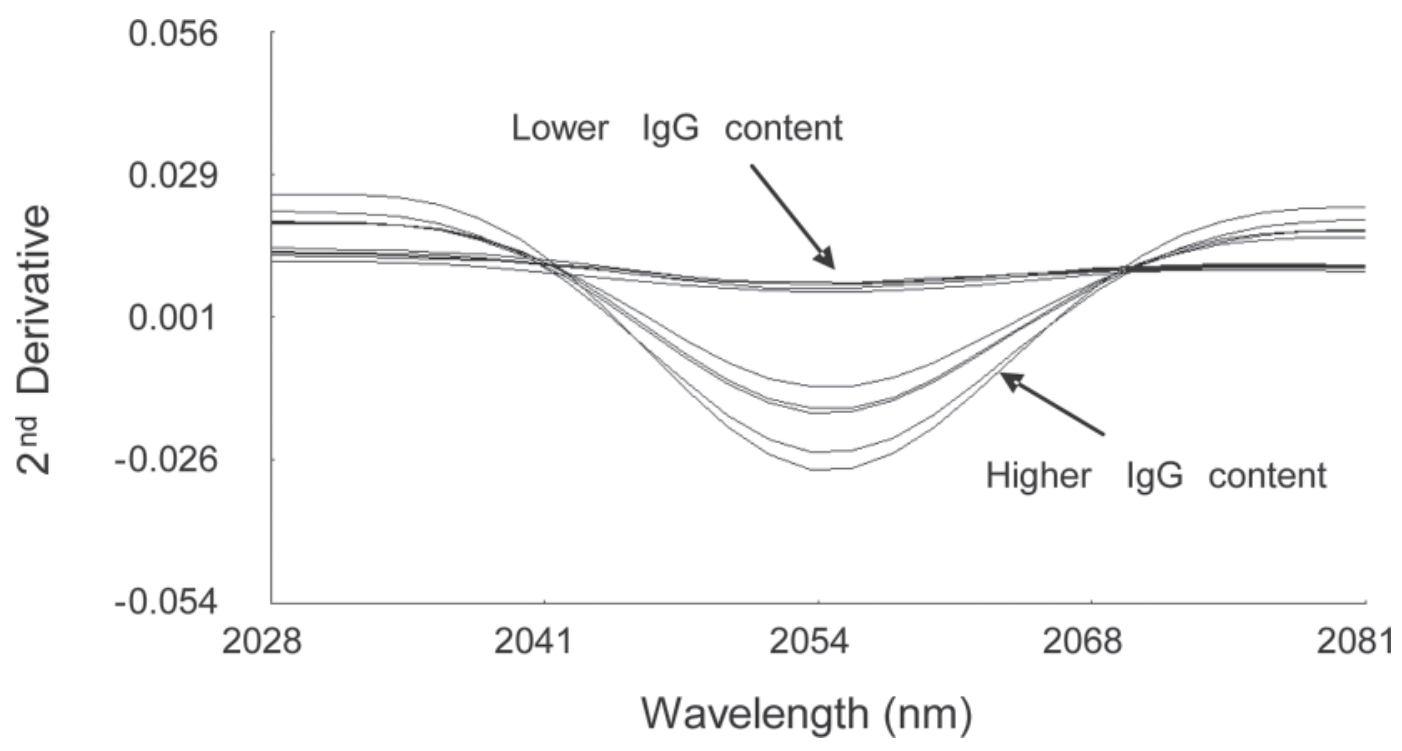

Figure 4. Second derivative of near infrared reflectance spectral segment (2,028 to 2,081 nm) of 5 colostrum samples with high IgG content and 5 with low $\mathrm{IgG}$ content. 


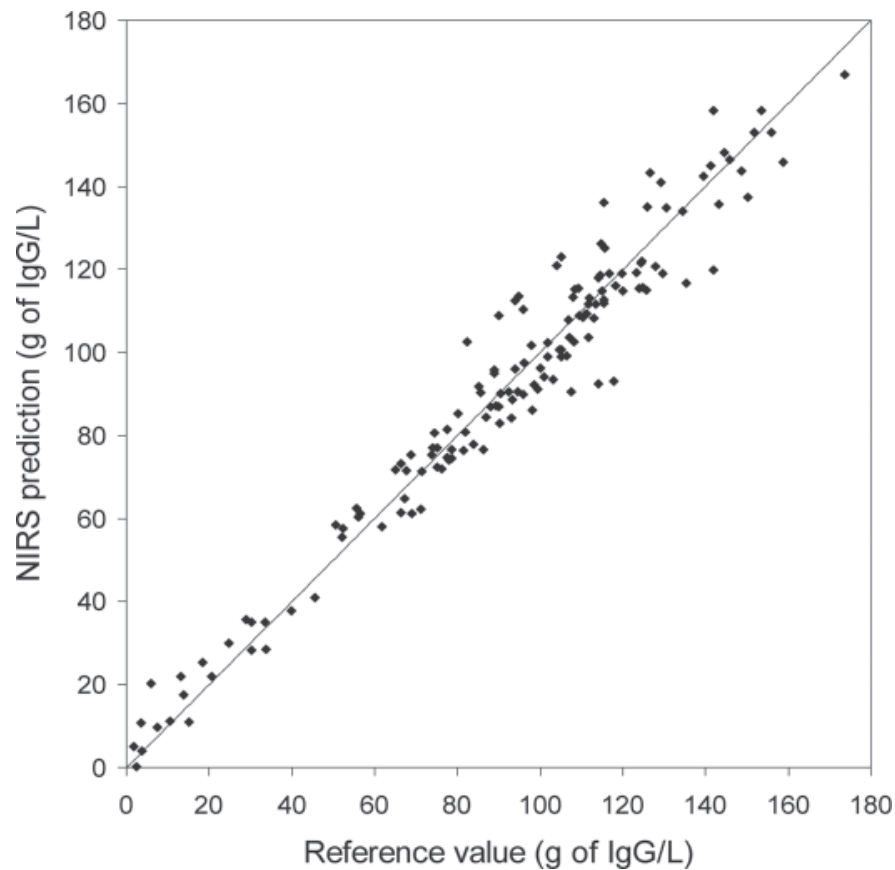

Figure 5. Near infrared reflectance spectroscopy (NIRS) predicted versus reference (radial immunodiffusion) values for IgG content $(\mathrm{g} / \mathrm{L})$ in bovine colostrum.

given the high proportion of the variation explained $\left(\mathrm{R}^{2} \mathrm{CV}\right)$ by the MPLS model. It is also apparent that the samples presented a wide and even distribution along the axis, although the model could probably be improved if more samples were included in the range of 40 to $60 \mathrm{~g} / \mathrm{L}$. Some samples in the lowest range of $\operatorname{IgG}$ content were slightly overestimated by the model, but, from a practical point of view, those colostrum samples would still be predicted as poor quality by the model.

\section{CONCLUSIONS}

Folded transmission (transflectance) is a fast and suitable technique to scan liquid colostrum samples. The VIS-NIR spectra can be used to develop regression models capable of obtaining reliable predictions of the content of IgG, and therefore to assess the passive immunity value of bovine colostrum. Modified partial least squares regression, along with a suitable mathematical treatment of the spectra, can be used to obtain such prediction models.

\section{ACKNOWLEDGMENTS}

The authors thank K\&M Farms (Valdivia, Chile) for providing the colostrum samples. The support of the personnel of the Laboratory of Animal Nutrition (Institute Animal Production, Faculty of Agricultural
Sciences, Universidad Austral de Chile, Valdivia) and of the Laboratory of Immunology (Department of Veterinary Microbiology, Western College of Veterinary Medicine, University of Saskatchewan, Saskatoon, Canada) for the NIRS and RID analysis, respectively, are gratefully acknowledged. Financial support for M. J. Rivero by means of a Doctoral Fellowship was provided by CONICYT (Chilean National Commission for Scientific and Technological Research).

\section{REFERENCES}

Abernethy, G., and D. Otter. 2010. Determination of immunoglobulin $\mathrm{G}$ in bovine colostrum and milk powders, and in dietary supplements of bovine origin by protein $\mathrm{G}$ affinity liquid chromatography: Collaborative study. J. AOAC Int. 93:622-627.

Argüello, A., N. Castro, and J. Capote. 2005. Evaluation of a color method for testing immunoglobulin $\mathrm{G}$ concentration in goat colostrum. J. Dairy Sci. 88:1752-1754.

Barnes, R. J., M. S. Dhanoa, and S. J. Lister. 1989. Standard normal variate transformation and de-trending of near-infrared diffuse reflectance spectra. Appl. Spectrosc. 43:772-777.

Barnes, R. J., M. S. Dhanoa, and S. J. Lister. 1993. Correction to the description of standard normal variate (SNV) and de-trend (DT) transformations in Practical Spectroscopy with Applications in Food and Beverage Analysis - 2nd edition. J. Near Infrared Spectrosc. 1:185-186.

Beam, A. L., J. E. Lombard, C. A. Kopral, L. P. Garber, A. L. Winter, J. A. Hicks, and J. L. Schlater. 2009. Prevalence of failure of passive transfer of immunity in newborn heifer calves and associated management practices on US dairy operations. J. Dairy Sci. 92:3973-3980.

Bielmann, V., J. Gillan, N. R. Perkins, A. L. Skidmore, S. Godden, and K. E. Leslie. 2010. An evaluation of Brix refractometry instruments for measurement of colostrum quality in dairy cattle. J. Dairy Sci. 93:3713-3721.

Bosco, G. L. 2010. Meeting Report. James L. Waters Symposium 2009 on Near-Infrared Spectroscopy. Trends Anal. Chem. 29:197-208.

Calderón, F., B. Chauveau-Duriot, B. Martin, B. Graulet, M. Doreau, and P. Nozière. 2007. Variations in carotenoids, vitamins A and $\mathrm{E}$, and color in cow's plasma and milk during late pregnancy and the first three months of lactation. J. Dairy Sci. 90:2335-2346.

Cen, H., and Y. He. 2007. Theory and application of near infrared reflectance spectroscopy in determination of food quality. Trends Food Sci. Technol. 18:72-83.

Chavatte, P., F. Clement, R. Cash, and J. F. Grongnet. 1999. Field determination of colostrum quality by using a novel, practical method. AAEP Proc. 44:206-209.

Chigerwe, M., J. W. Tyler, J. R. Middleton, J. N. Spain, J. S. Dill, and B. J. Steevens. 2008. Comparison of four methods to assess colostral IgG concentration in dairy cows. J. Am. Vet. Med. Assoc. 233:761-766.

Dolman, C., and R. Thorpe. 2002. Analysis and purification of IgG using size-exclusion high performance liquid chromatography (SEHPLC). Pages 995-997 in The Protein Protocols Handbook. J. M. Walker, ed, Humana Press, Totowa, NJ.

Dračková, M., L. Hadra, B. Janštová, P. Navrátilová, H. Přidalová, and L. Vorlová. 2008. Analysis of goat milk by near-infrared spectroscopy. Acta Vet. (Brno) 77:415-422.

El-Loly, M. M. 2007. Bovine milk immunoglobulins in relation to human health. Int. J. Dairy. Sci. 2:183-195.

Farrell, H. M., R. Jimenez-Flores, G. T. Bleck, E. M. Brown, J. E. Butler, L. K. Creamer, C. L. Hicks, C. M. Hollar, K. F. Ng-KwaiHang, and H. E. Swaisgood. 2004. Nomenclature of the proteins of cows' milk-Sixth revision. J. Dairy Sci. 87:1641-1674.

Gapper, L. W., D. E. J. Copestake, D. E. Otter, and H. E. Indyk. 2007. Analysis of bovine immunoglobulin G in milk, colostrum and dietary supplements: A review. Anal. Bioanal. Chem. 389:93-109. 
Givens, D. I., J. L. De Boever, and E. R. Deaville. 1997. The principles, practices and some future applications of near infrared spectroscopy for predicting the nutritive value of foods for animals and humans. Nutr. Res. Rev. 10:83-114.

Hopkins, D. W. 2001. What is a Norris derivative? NIRnews 12:3-5.

Hruschka, W. R. 2001. Data analysis: Wavelength selection methods. Pages 39-58 in Near-Infrared Technology in the Agricultural and Food Industries. P. Williams and K. Norris, ed. American Association of Cereal Chemists, St Paul, MN.

Kawamura, S., M. Kawasaki, H. Nakatsuji, and M. Natsuga. 2007. Near-infrared spectroscopic sensing system for online monitoring of milk quality during milking. J. Sens. Instrum. Food Qual. Safety 1:37-43.

Kehoe, S. I., B. M. Jayarao, and A. J. Heinrichs. 2007. A survey of bovine colostrum composition and colostrum management practices on Pennsylvania dairy farms. J. Dairy Sci. 90:4108-4116.

Korhonen, H., P. Marnila, and H. S. Gill. 2000. Milk immunoglobulins and complement factors. Br. J. Nutr. 84:S75-80.

Laporte, M.-F., and P. Paquin. 1999. Near-infrared analysis of fat, protein, and casein in cow's milk. J. Agric. Food Chem. 47:26002605.

Mancini, G., A. O. Carbonara, and J. F. Heremans. 1965. Immunochemical quantitation of antigens by single radial immunodiffusion. Immunochemistry 2:235-254.

Mark, H. 2008. Data analysis: Multilinear regression and principal component analysis. Pages 151-188 in Handbook of Near Infrared Analysis. D. A. Burns and E. W. Ciurczak, ed. CRC Press, Boca Raton, FL.

Miller, C. E. 2001. Chemical principles of near infrared technology. Pages 19-37 in Near-Infrared Technology in the Agricultural and Food Industries. P. Williams and K. Norris, ed. American Association of Cereal Chemists, St Paul, MN.

Murray, I. 1986. Near infrared reflectance analysis of forages. Pages 141-156 in Recent Advances in Animal Nutrition. W. Heresign, and D. J. A. Cole, ed. Butterworths, London, UK.

Navrátilová, P., L. Hadra, M. Dracková, B. Janstová, L. Vorlová, and L. Pavlata. 2006. Use of FT-NIR spectroscopy for bovine colostrum analysis. Acta Vet. (Brno) 75:57-63.

Norris, K. H. 2001. Understanding and correcting the factors which affect diffuse transmittance spectra. NIRnews 12:6-9.

Osborne, B. G., T. Fearn, and P. H. Hindle. 1993. Practical NIR Spectroscopy with Applications on Food and Beverage Analysis. Longman Scientific and Technical, Burnt Mill, Harlow, UK.

Page, M., and R. Thorpe. 2002. Analysis of IgG fractions by electrophoresis. Pages 1005-1007 in The Protein Protocols Handbook. J. M. Walker, ed. Humana Press, Totowa, NJ.

Robert, P., M. F. Devaux, and D. Bertrand. 1996. Beyond prediction: Extracting relevant information from near infrared spectra. J. Near Infrared Spectrosc. 4:75-84.
Rudovsky, A., L. Locher, A. Zeyner, A. Sobiraj, and T. Wittek. 2008. Measurement of immunoglobulin concentration in goat colostrums. Small Rumin. Res. 74:265-269.

Šašic, S., and Y. Ozaki. 2001. Short-wave near-infrared spectroscopy of biological fluids. 1. Quantitative analysis of fat, protein, and lactose in raw milk by partial least-squares regression and band assignment. Anal. Chem. 73:64-71.

Shenk, J. S., and M. Westerhaus. 1996. Calibration the ISI way. Pages 198-202 in Near-Infrared Spectroscopy: The Future Waves. A. M. C. Davies and P. C. Williams, ed. NIR Publications, Chichester, UK.

Stelwagen, K., E. Carpenter, B. Haigh, A. Hodgkinson, and T. T. Wheeler. 2009. Immune components of bovine colostrum and milk. J. Anim. Sci. 87(13 Suppl.):3-9.

Tsenkova, R., S. Atanassova, K. Itoh, Y. Ozaki, and K. Toyoda. 2000 Near infrared spectroscopy for biomonitoring: Cow milk composition measurement in a spectral region from 1,100 to 2,400 nanometers. J. Anim. Sci. 78:515-522.

Tsenkova, R., S. Atanassova, S. Kawano, and K. Toyoda. 2001. Somatic cell count determination in cow's milk by near-infrared spectroscopy: A new diagnostic tool. J. Anim. Sci. 79:2550-2557.

Tyler, W., B. J. Steevens, D. E. Hostetler, J. M. Holle, and J. L. Denbigh. 1999. Colostral immunoglobulin concentrations in Holstein and Guernsey cows. Am. J. Vet. Res. 60:1136-1139.

Wheeler, T. T., A. J. Hodgkinson, C. G. Prosser, and S. R. Davis. 2007. Immune components of colostrum and milk-A historical perspective. J. Mammary Gland Biol. Neoplasia 12:237-247.

Williams, P. C. 2001. Implementation of near-infrared technology. Pages 145-169 in Nearinfrared Technology in the Agricultural and Food Industries. P. C. Williams and K. H. Norris, ed. American Association of Cereal Chemists, St Paul, MN.

Williams, P. C., and K. Norris. 2001. Variables affecting near-infrared spectroscopic analysis. Pages 171-185 in Nearinfrared Technology in the Agricultural and Food Industries. P. C. Williams and K. H. Norris, ed. American Association of Cereal Chemists, St Paul, $\mathrm{MN}$.

Williams, P. C., and D. Sobering. 1996. How do we do it: A brief summary of the methods we use in developing near-infrared calibrations. Pages 185-188 in Near-Infrared Spectroscopy: The Future Waves. A. M. C. Davies and P. C. Williams, ed. NIR Publications, Chichester, UK.

Wu, D., Y. He, S. Feng, and D. W. Sun. 2008. Study on infrared spectroscopy technique for fast measurement of protein content in milk powder based on LS-SVM. J. Food Eng. 84:124-131. 